Article

\title{
Feasibility of Using Gangue and Fly Ash as Filling Slurry Materials
}

\author{
Hao Wang ${ }^{1, *} \mathbb{D}$, Jian Jiao ${ }^{1}$, Yumin Wang ${ }^{1}$ and Weisheng $\mathrm{Du}^{2}$ \\ 1 College of Resources \& Safety Engineering, China University of Mining \& Technology, Beijing, \\ D11 Xueyuan Road, Haidian District, Beijing 100083, China; jiaojian@student.cumtb.edu.cn (J.J.); \\ Emmie.WYM@outlook.com (Y.W.) \\ 2 State Key Laboratory of Hydroscience and Engineering, Tsinghua University, Haidian District, \\ Beijing 100084, China; duweisheng1225@126.com \\ * Correspondence: TBP1600101006@student.cumtb.edu.cn; Tel.: +86-188-1139-7619
}

Received: 14 October 2018; Accepted: 19 November 2018; Published: 22 November 2018

check for updates

\begin{abstract}
When used as filling aggregates, the physical and mechanical properties of gangue and fly ash are crucial for the design of filling and transportation systems. The mineral composition of gangue and fly ash affects the filling body's strength, and the fluidity of the slurry affects the mining engineering process. In this study, gangue and fly ash samples were characterized by X-ray diffraction to ensure their suitability as filling materials. Tests were carried out with an Intelligent Torque Rheometer, and the optimal ratio of the slurry's components was determined. After fitting the data using ORIGIN software, the following curves were obtained: (1) rheological parameters versus slurry mass fraction; (2) rheological parameters versus component ratio. On the basis of the curves, the recommended ratio of the components in the paste-like slurry was determined. We found that the mass concentration of the slurry must be kept strictly below $78 \%$, and the optimal slurry composition includes coal gangue, fly ash, and a gelling agent at a weight ratio of 8:3:1. In order to illustrate the effectiveness of the filling technology, surface sink curves from different filling techniques in two closely situated positions of the Xinyang Coal Mine were compared. The results showed that the use of a paste-like slurry can effectively reduce surface subsidence. Furthermore, it will lead to cost-effective engineering designs for the sustainable development of coal mines.
\end{abstract}

Keywords: green mining; paste-like slurry; XRD; intelligent torque rheometer; on-site monitoring

\section{Introduction}

Gangue and fly ash are common industrial waste products, which are occupying an increasingly large area of land and polluting the environment. The coal mining method of paste-like slurry filling exemplifies the application and characteristics of green mining from the perspective of both resource recycling and waste reuse. In 2017, China's coal production was about $3.5 \times 10^{9}$ tons, of which $2.5 \times 10^{9}$ tons came from underground mining [1]. Coal gangue is a kind of waste rock generated during coal mining and processing. It is collected from roofs, floors, mezzanines, and meteorites during roadway tunneling, and washed gangue is generated during coal washing. According to incomplete statistics, about $5 \times 10^{9}$ tons of waste gangue has been deposited on the surface, and over 1600 large-scale waste dumps occupy a landmass of approximately $1.5 \times 10^{7} \mathrm{hm}^{2}[2,3]$. The annual increase in the mining subsidence area is about $5 \times 10^{4} \mathrm{hm}^{2}$; the area related to coal resource exploitation is about $0.2 \mathrm{hm}^{2}$ of subsidence per $10^{4}$ tons of coal yield. Sulfur, phosphorus, carbon, and dozens of components in waste coal (wasted coal refers to the coal mixed in the gangue or attached to the surface of the gangue) combined with spontaneous combustion cause various degrees of pollution in the atmosphere, water, soil, and so forth. In addition, if rainwater infiltrates a spontaneously combusting waste dump, 
the rapid expansion of heated air will cause an explosion [4]. Increased fuel consumption has led to an increasingly prominent contradiction between the concern for resource exhaustion and environmental destruction and the interest in economic development $[5,6]$.

There are several methods for filling a goaf: solid or direct backfilling, hydraulic filling, cemented filling, and so on [7-9]. Every filling method has its disadvantages. As for the gangue filling method, it is difficult to monitor the filling body's strength and stability, while, for the cement filling process, the performance of the cementing material is strict [10]; in addition, with the paste filling method it is easy to block the pipe because of the high concentration of the filling material [11], whereas the high water filling technology is uneconomical [12]. In the 2000s, paste-like backfilling methods were developed in coal mines. The slurry was made of gangue and fly ash at concentrations that could be higher than $75 \%$, and a gelling agent was added at a concentration of about $3-5 \%$ in order to rapidly consolidate the body and achieve high strength. The high mass concentration of the slurry resulted in an appearance similar to toothpaste. The paste-like filling technology has many remarkable advantages, such as extensive resource recovery, low cost, minimum environmental pollution, simple preparation technology, efficient transportation, and a filling body with high strength $[13,14]$. Applied to coal mining under buildings, railways, and water bodies, the technology effectively controls the surrounding rock reformation and subsidence, raises the resource recovery ratio, and realizes its goal without waste and harm [15].

A paste-like slurry is a mixture of gangue particles, fly ash, cement, and water. Gangue particles and fly ash are aggregates in the paste-like slurry. The widely present floc structures in water at a certain mass concentration maintain fluid homogeneity [16], and the coarse gangue particles are deposited slowly and freely in the homogeneous slurry. With the increase in mass concentration, the coarse particles are increasingly enveloped and become components of the slurry. When the slurry mass concentration exceeds a certain critical threshold, the entire fluid is converted into a homogeneous slurry [17]. The fluid is termed a heterogeneous-homogeneous composite fluid, which is a typical kind of Bingham fluid with good fluidity. The resistance of the composite flow is much lower than the resistance of a non-homogeneous flow in the same conditions [14]. Generally speaking, the effective and successful filling of the goaf with the slurry should guarantee a strength of the filling body that is sufficient to support roofs and to effectively transport material [16-18]. The physical composition and form of the material have a significant effect on the strength of the filling body $[15,19]$. X-ray diffraction (XRD) is usually used to identify the mineralogical phases of natural and anthropogenic materials. In this study, gangue and fly ash sample characterizations were performed by XRD first, and then a torque rheometer was used to determine the ratio of the slurry components. On the basis of a large number of experiments, the following curves were obtained: (1) rheological parameters versus slurry mass concentration and (2) rheological parameters versus composition ratio. On the basis of the trends of the curves, the optimum concentration of the slurry components and the optimum group distribution ratio were determined. An ill-proportioned ratio will inevitably affect the rheological properties of the slurry, thereby causing filling accidents, and the filling cost will rise. Limited by experimental equipment, the ratio of the paste-like slurry components has always been based on experience or a large number of similar tests [20-22]. This is a waste of materials and work. The new equipment described here not only avoids these drawbacks but also improves the accuracy of the results.

There have been many studies on surface sink caused by mining [23-26]. Previous research has shown that filling materials could meet the requirements to support the roof. Research has further shown the feasibility of using gangue and fly ash as filling materials and the resulting fluidity of the slurry, as well as the high efficiency of coal production and its environmental sustainability. 


\section{X-Ray Diffraction Experiment}

\subsection{Sample Preparation}

As the main parts of the filling slurry, the basic physical and mechanical properties of gangue and fly ash are crucial for the design of filling and transportation systems. The mineral composition of washed gangue and fly ash affects the filling body's strength, and the fluidity of the slurry affects the planning process.

Gangue samples were collected from the Xinyang Coal Mine in Gaoyang Town, Xiaoyi City, Shanxi Province, and fly ash was collected from a thermal power station in Wutong Town, which is 20 miles away from Gaoyang Town.

\subsection{X-Ray Diffraction of Samples}

The equipment used was a D/Max-3B X-ray diffractometer manufactured by Rigaku Corporation, Tokyo, Japan. Powder X-ray diffraction profiles were measured using the diffractometer (with $\mathrm{Cu}-\mathrm{K} \alpha$ radiation) equipped with a curved graphite monochromator. The slit system was set as follows: DS: $1^{\circ}$; RS: $1^{\circ}$; SS: $0.15 \mathrm{~mm}$; RSM: $0.6^{\circ}$. The voltage and electric current of the $X$-ray generator were $35 \mathrm{kV}$ and $30 \mathrm{~mA}$. The speed of continuous scanning in the qualitative analysis was $3^{\circ} / \mathrm{min}$, and the sampling interval was $0.02^{\circ}$. The speed of continuous scanning in the quantitative analysis was $0.25^{\circ} / \mathrm{min}$, and the sampling interval was $0.01^{\circ}$.

On the basis of the K-value method of the Chinese standard (GB5225-86), the composition of washed gangue was determined and is shown in Table 1, while the X-ray diffraction spectrum is shown in Figure 1. The composition of fly ash is shown in Table 2, and the X-ray diffraction spectrum is shown in Figure 2.

Table 1. Chemical composition of washed gangue.

\begin{tabular}{cccccccccc}
\hline Sample & $\mathbf{N a}_{\mathbf{2}} \mathbf{O}$ & $\mathbf{M g O}$ & $\mathbf{A l}_{2} \mathbf{O}_{3}$ & $\mathrm{SiO}_{2}$ & $\mathbf{K}_{\mathbf{2}} \mathbf{O}$ & $\mathbf{C a O}$ & $\mathbf{F e}_{2} \mathbf{O}_{3}$ & $\mathbf{P}$ & $\mathbf{S}$ \\
\hline Washed Gangue (\%) & 1.2 & 1.2 & 24.3 & 53.1 & 1.3 & 5.4 & 1.9 & 0.03 & 0.8 \\
\hline
\end{tabular}

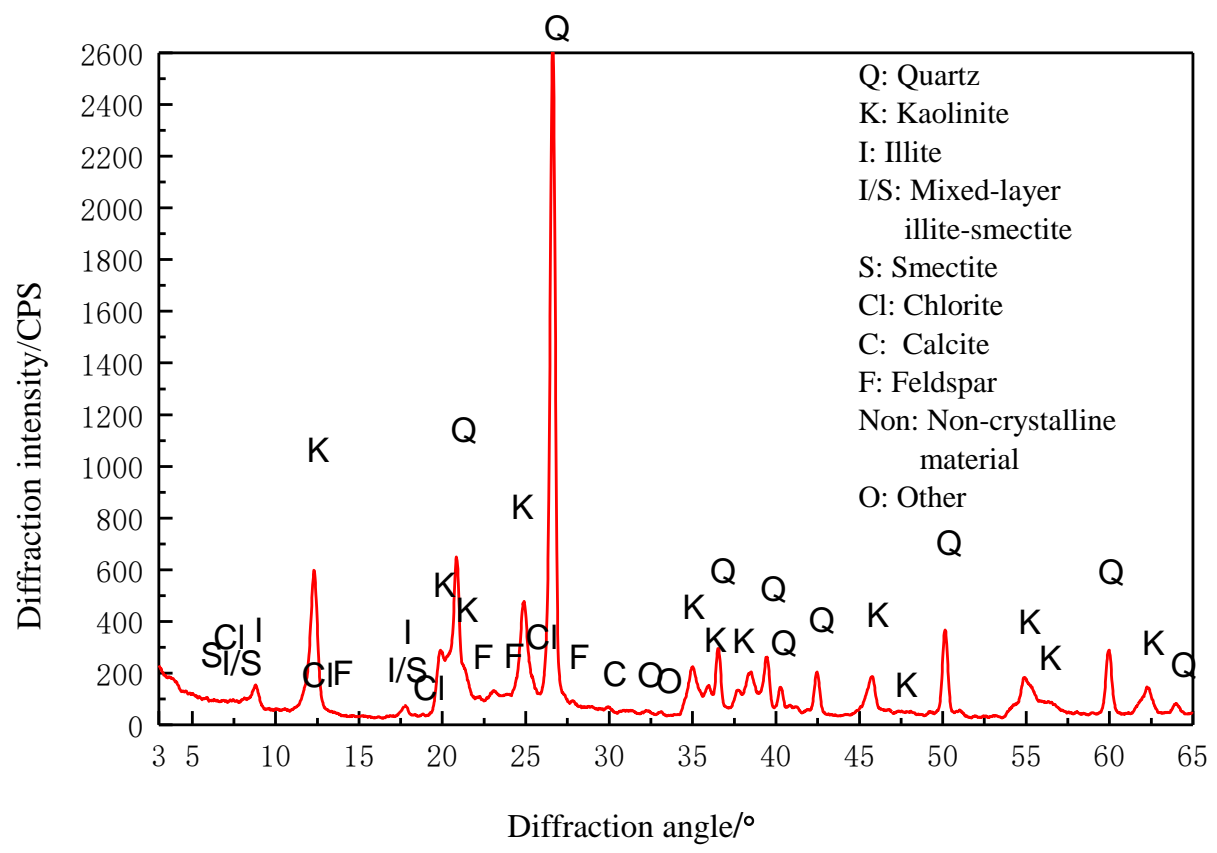

Figure 1. X-ray diffraction spectrum of washed gangue. 
Table 2. Chemical composition of fly ash.

\begin{tabular}{cccccccccc}
\hline Sample & $\mathrm{Na}_{2} \mathrm{O}$ & $\mathbf{M g O}$ & $\mathrm{Al}_{2} \mathbf{O}_{3}$ & $\mathbf{S i O}_{2}$ & $\mathbf{K}_{\mathbf{2}} \mathbf{O}$ & $\mathbf{C a O}$ & $\mathrm{Fe}_{2} \mathbf{O}_{3}$ & $\mathbf{P}$ & $\mathbf{S}$ \\
\hline Fly Ash (\%) & 1.5 & 1.2 & 25.5 & 48.8 & 0.6 & 4.2 & 4.7 & 0.07 & 1.0 \\
\hline
\end{tabular}

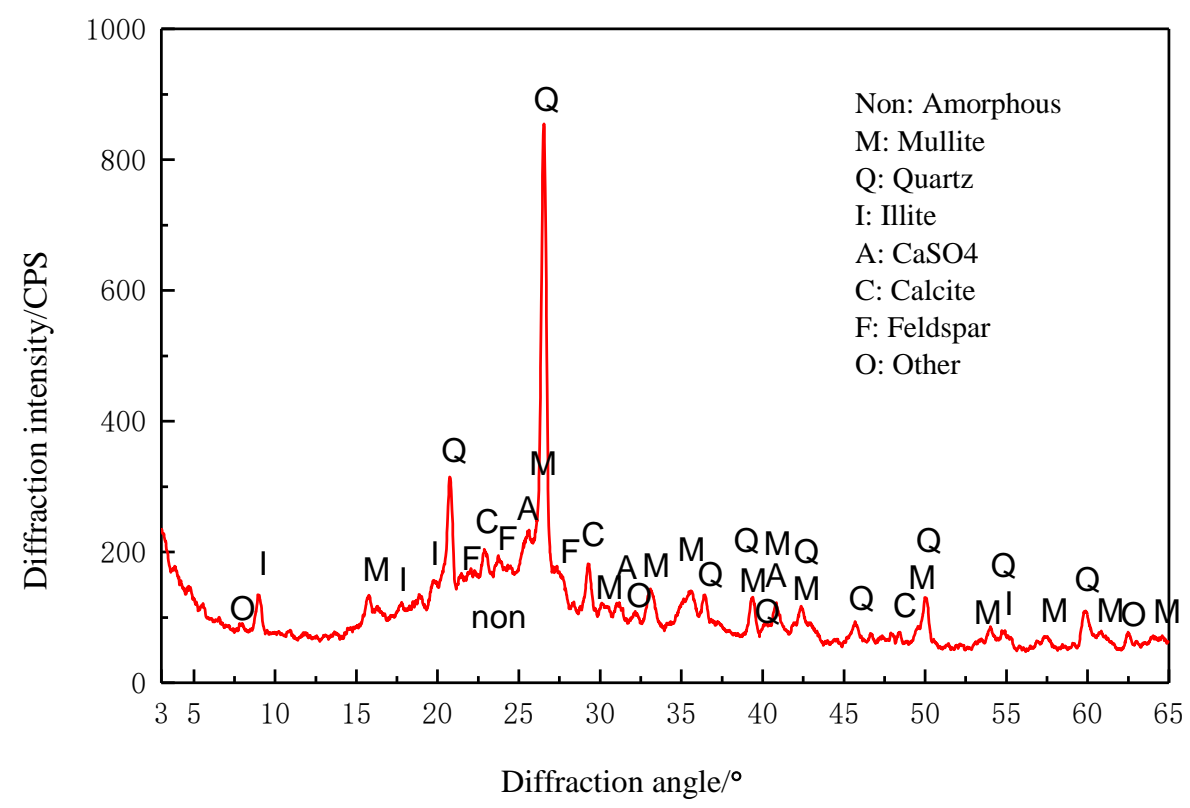

Figure 2. X-ray diffraction spectrum of fly ash.

Comparative analyses with the standard powder diffraction data of various substances, provided by the Powder Diffraction Federation International Data Center (JCPDS-ICDD), were performed. The analyses show that the main components of the washed gangue were quartz, kaolinite, some illite, mixed-layer illite-smectite, non-crystalline materials, and a small quantity of other minerals, some of which may be considered coal or another substance. The main components of fly ash were non-crystalline; it contained slightly more quartz than gangue, some minerals, such as mixed-layer illite-smectite, and illite, and small amounts of calcite, $\mathrm{CaSO}_{4}$, and feldspar. The non-crystalline material in the sample can be produced by heating the clay at a moderate temperature. The results showed that $\mathrm{SiO}_{2}$ was the main component of gangue and fly ash, an attribute that would impart high strength to the filling body.

\section{Development of the Intelligent Torque Rheometer and Rheological Experiments of the Paste-like Slurry}

\subsection{Development of the Intelligent Torque Rheometer}

The paste-like slurry was made of coarse particles, fine particles, and water. The coarse particle was coal gangue, crushed to a size smaller than $20 \mathrm{~mm}$ in situ. The fine particle was fly ash, and the gelling agent was Portland cement.

Because the maximum size of the coarse particles in the paste-like slurry was about $20 \mathrm{~mm}$, the slurry could not be measured by normal rheometers. On the basis of rheometer principles and a torque sensor, an intelligent torque rheometer was developed. Figure 3 presents the intelligent torque rheometer, and Figure 4 shows a schematic of the Intelligent Torque Rheometer.

The most important part of the intelligent torque rheometer is a high-sensitivity iron piece leaf which can measure small deformations. When the iron piece leaf rotates at a speed of $\omega$, the slurry will be driven to rotate in different layers. The slurry's initial resistance causes the iron leaf to deform. 
The shape variables $(\gamma)$ occurring at different radii $(r)$ are different. The angular velocity of the position at $r+d r$ is $\omega+d \omega$.

$$
\begin{gathered}
d \gamma=\frac{(r+d r)(\omega+d \omega) d t-(r+d r) \omega d t}{d r}=\frac{r d \omega-d r d \omega}{d r} \approx r \frac{d \omega}{d r} d t \\
\frac{d \gamma}{d t}=r \frac{d \omega}{d r}
\end{gathered}
$$

With the initial shear stress of the slurry expressed as $\tau_{0}$, Equation (3) can be established:

$$
\tau=\tau_{0}+\eta \frac{d \gamma}{d t}=\tau_{0}+\eta r \frac{d \omega}{d r}
$$

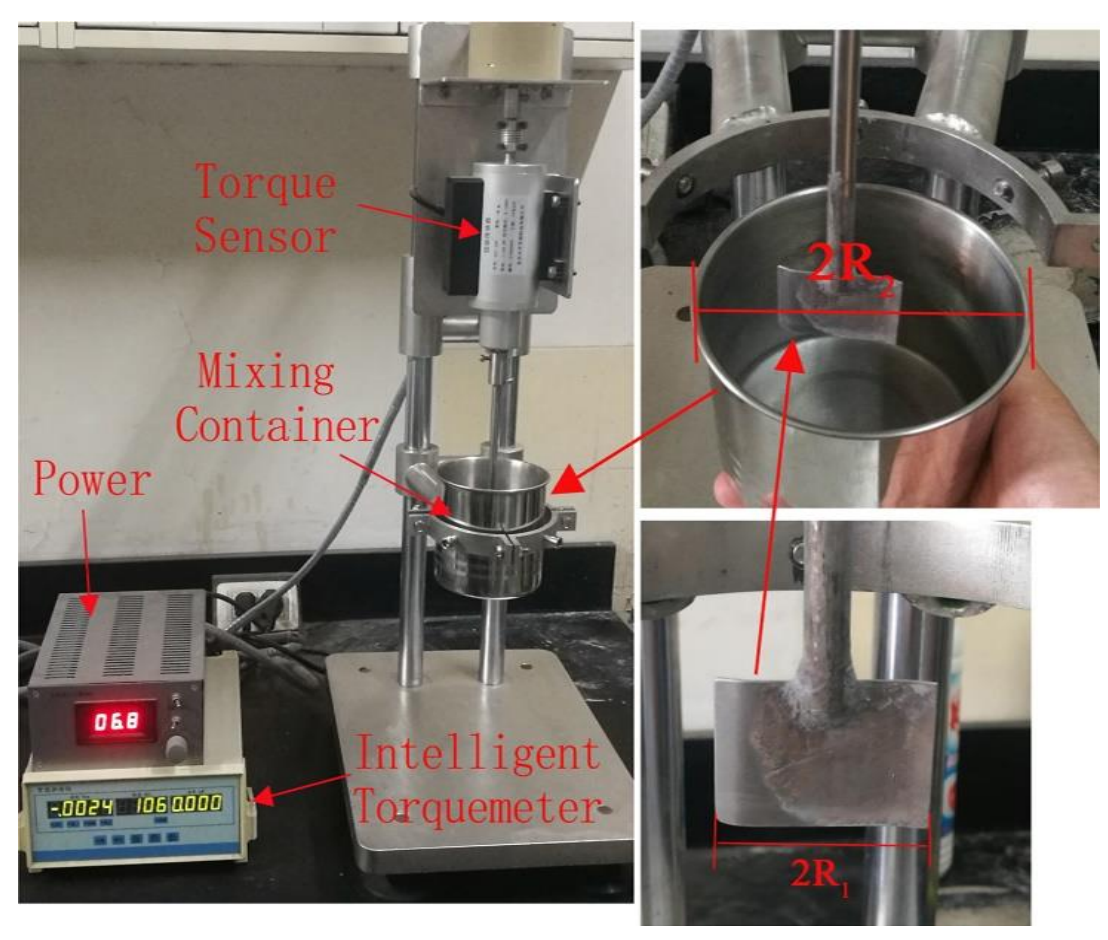

Figure 3. Intelligent Torque Rheometer.

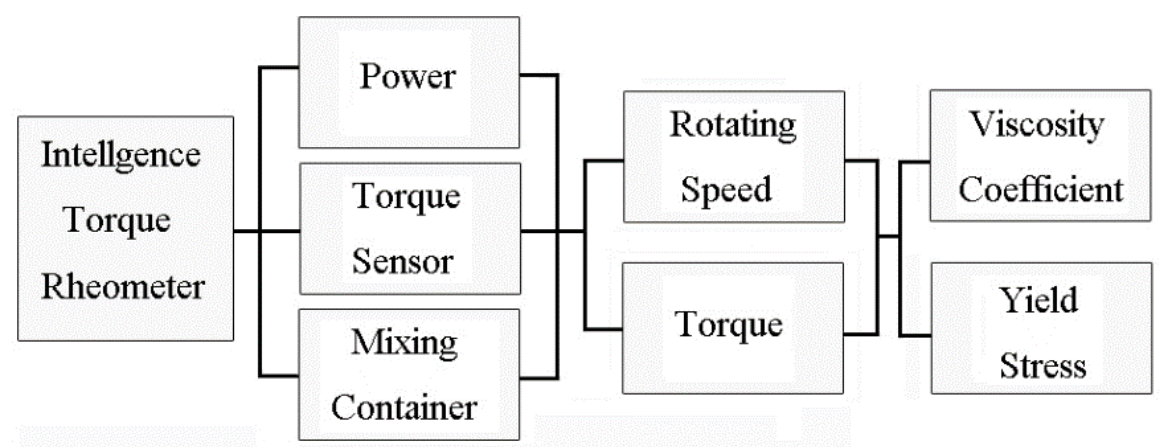

Figure 4. Schematic of the Intelligent Torque Rheometer.

The moment $M$ is:

$$
\begin{gathered}
M=\tau \cdot 2 \pi r h r=2 \pi r^{2} h\left(\tau_{0}+\eta r \frac{d \omega}{d r}\right) \\
d \omega=\left(\frac{M}{2 \pi h \eta r^{3}}-\frac{\tau_{0}}{\eta r}\right) d r
\end{gathered}
$$


Then, the formula's integral is obtained:

$$
\int_{0}^{\alpha} d \omega=\int_{R_{1}}^{R_{2}}\left(\frac{M}{2 \pi h \eta r^{3}}-\frac{\tau_{0}}{\eta r}\right) d r
$$

Finally, the rheological parameters of the slurry can be calculated by Equation (7),

$$
\begin{gathered}
\omega=\frac{M}{4 \pi h \eta}\left(\frac{1}{R_{1}^{2}}-\frac{1}{R_{2}^{2}}\right)-\frac{\tau_{0}}{\eta} \ln \frac{R_{2}}{R_{1}} \\
M=\frac{4 \pi h \eta}{\frac{1}{R_{1}^{2}}-\frac{1}{R_{2}^{2}}} \cdot \omega+\tau_{0} \cdot \frac{4 \pi h}{\frac{1}{R_{1}^{2}}-\frac{1}{R_{2}^{2}}} \cdot \ln \frac{R_{2}}{R_{1}}
\end{gathered}
$$

where $R_{1}$ is the radius of the high-sensitivity iron piece leaf; $R_{2}$ is the radius of the mixing container; $h$ is the height of the high-sensitivity iron piece leaf; $M$ is the torque; $\eta$ is the viscosity coefficient; $\tau_{0}$ is the initial shear stress; $\omega$ is the rotating speed.

\subsection{Calibration for the Intelligent Torque Rheometer}

In order to obtain the true torque, the Anton Paar RheolabQC rheometer (Anton Paar RheolabQC rheometer, Graz, Austria) was used as a calibration instrument for accurately testing the rheological properties of Newtonian and non-Newtonian fluids and calibrate the intelligent torque rheometer. Figure 5 shows the Anton Paar RheolabQC rheometer.

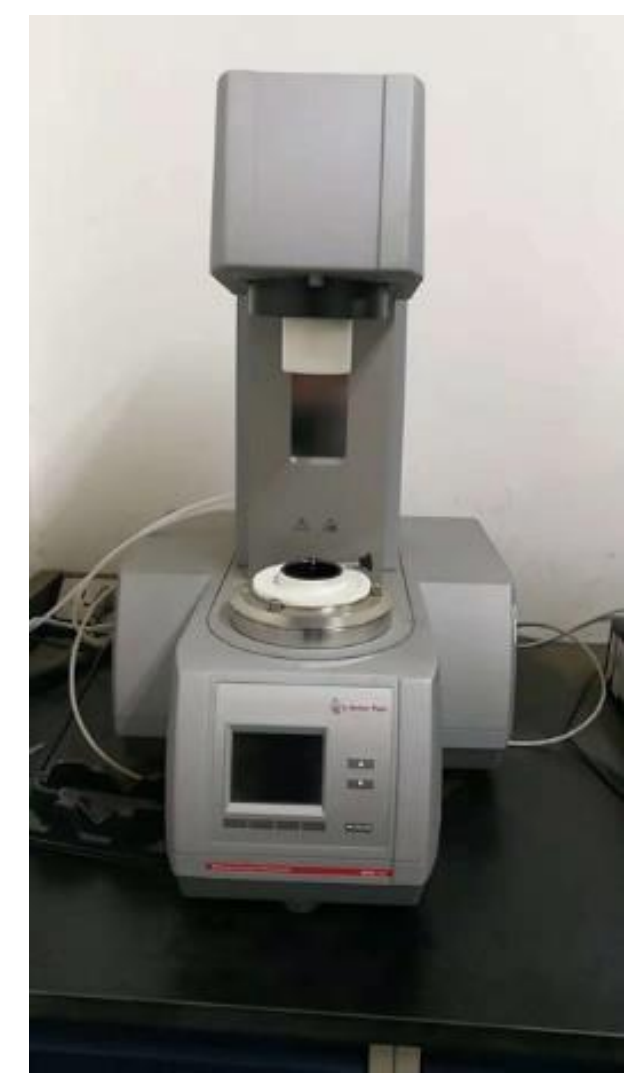

Figure 5. Anton Paar RheolabQC Rheometer.

The measured torque, named $M 1$, and the actual torque, named $M$, can be represented by Equation (9):

$$
M=k M_{1}+a
$$


where $M$ is the actual torque; $M_{1}$ is the measured torque.

The torques and rotation speeds of slurries with different concentrations were measured using the RheolabQC rheometer and the intelligent torque rheometer and were then compared. Equation (9) was used in the process. Finally, the values of $k$ and $a$ were obtained. The test indicators of the RheolabQC rheometer are shown in Table 3.

Table 3. Viscometer test indicators.

\begin{tabular}{ccccc}
\hline Power & Measuring Range $(\boldsymbol{\eta})$ & Shear Stress $(\boldsymbol{\tau})$ & Shear Rate (Ds) & Rotating Speed $(\boldsymbol{n})$ \\
\hline $220 \pm 22 \mathrm{~V}$ & 1 to $10^{9} \mathrm{mPa} \cdot \mathrm{s}$ & 0.5 to $10^{4} \mathrm{~Pa}$ & $10^{-2}$ to 6500 & $0.01 \sim 1200 \mathrm{r} / \mathrm{min}$ \\
$50 \pm 0.5 \mathrm{~Hz}$ & & & & \\
\hline
\end{tabular}

Since the calibration instrument is mainly suitable for measuring a non-Newtonian fluid slurry, the experimental material was a mixture of tailings and fly ash. The slurry parametric test results are shown in Table 4.

Table 4. Slurry parametric test.

\begin{tabular}{cccc}
\hline $\begin{array}{c}\text { Mass } \\
\text { Concentration }\end{array}$ & $\begin{array}{c}\text { Viscosity } \\
\text { Coefficient/Pa.s }\end{array}$ & $\begin{array}{c}\text { Initial Shear } \\
\text { Stress/Pa }\end{array}$ & The Relation of M- $\boldsymbol{\omega}$ \\
\hline $54 \%$ & 0.040 & 1.626 & $M=1.76 \times 10^{-5} \omega+1.66 \times 10^{-4}$ \\
$56 \%$ & 0.042 & 3.179 & $M=1.89 \times 10^{-5} \omega+3.21 \times 10^{-4}$ \\
$58 \%$ & 0.045 & 5.961 & $M=2.09 \times 10^{-5} \omega+5.88 \times 10^{-4}$ \\
$60 \%$ & 0.074 & 8.847 & $M=3.31 \times 10^{-5} \omega+8.74 \times 10^{-4}$ \\
\hline
\end{tabular}

The rheological properties corresponding to different concentrations showed that the initial shear stress increased as the slurry concentration increased. When the slurry concentration was 54-58\%, the plastic viscosity of the slurry changed gently. When the concentration was higher than $60 \%$, the plastic viscosity of the slurry increased drastically. The rheological properties curve of the slurry was fitted by ORIGIN software (Northampton, MA, USA) and showed obvious characteristics of a Bingham fluid. Using ORIGIN, the measured torques were fitted with the actual torque, and the fitted regression line is shown in Figure 6.

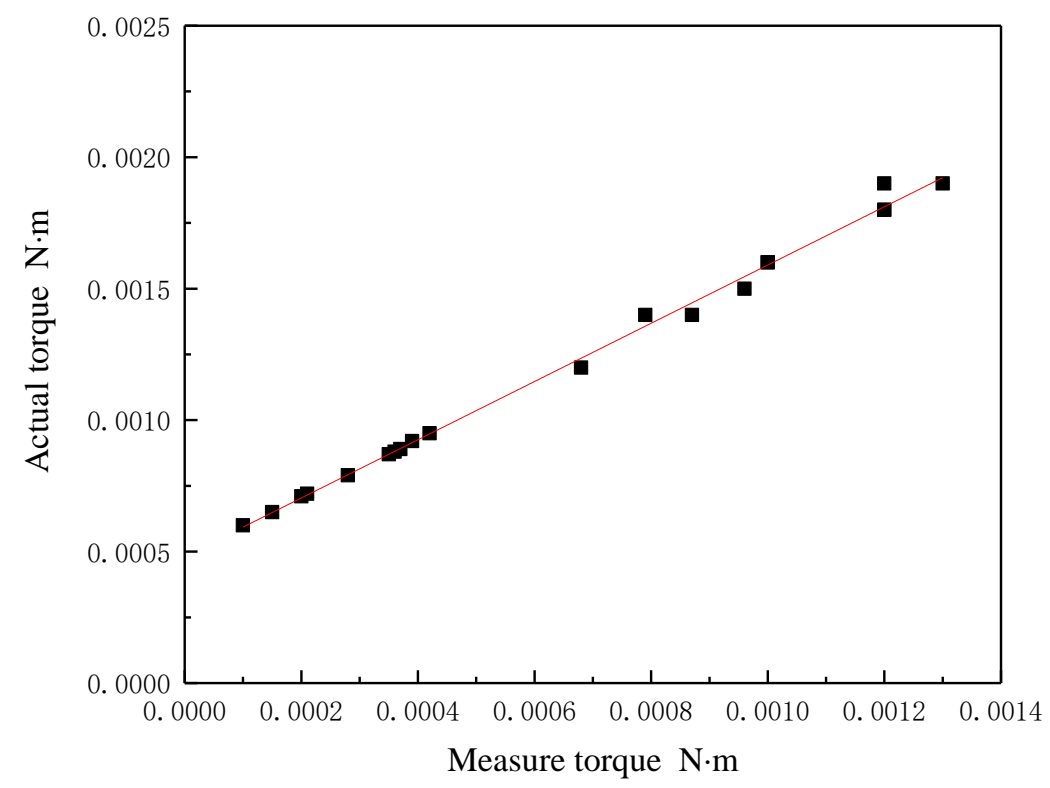

Figure 6. Torque comprehensive regression curve. 
The formula relating the measured torque to the actual torque is shown in Equation (10):

$$
M=1.107 M_{1}+4.825 \times 10^{-4}
$$

According to Equation (8), the parameters of the Intelligent Torque Rheometer are: $R_{1}=2 \mathrm{~cm}$, $R_{2}=5 \mathrm{~cm}, h=3 \mathrm{~cm}$. The relation between torque and rotating speed can be determined by Equation (11):

$$
M=1.787 \times 10^{-4} \eta \cdot \omega+1.638 \times 10^{-4} \tau_{0}
$$

Table 5 shows the test values under different concentrations.

Table 5. Test values under different concentrations.

\begin{tabular}{cccc}
\hline Mass Concentration & Rotating Speed $\mathbf{r} / \mathbf{m i n}$ & Measured Torque $\mathbf{N} \cdot \mathbf{m}$ & Actual Torque $\mathbf{N} \cdot \mathbf{m}$ \\
\hline \multirow{3}{*}{$54 \%$} & 220 & 0.00015 & 0.00065 \\
& 260 & 0.00021 & 0.00072 \\
& 330 & 0.00035 & 0.00087 \\
370 & 0.00037 & 0.00089 \\
400 & 0.00042 & 0.00095 \\
\hline \multirow{2}{*}{$56 \%$} & 240 & 0.0001 & 0.0006 \\
& 270 & 0.0002 & 0.00071 \\
& 340 & 0.00028 & 0.00079 \\
& 380 & 0.00036 & 0.00088 \\
& 420 & 0.00039 & 0.00092 \\
\hline & 260 & 0.00087 & 0.0014 \\
& 300 & 0.00096 & 0.0015 \\
& 330 & 0.001 & 0.0016 \\
& 410 & 0.0012 & 0.0018 \\
& 460 & 0.0012 & 0.0019 \\
\hline & 220 & 0.00068 & 0.0012 \\
& 260 & 0.00079 & 0.0014 \\
& 320 & 0.001 & 0.0016 \\
& 340 & 0.0012 & 0.0018 \\
& 380 & 0.0013 & 0.0019 \\
\hline
\end{tabular}

In order to reduce measurement errors with the intelligent torque rheometer, the following requirements should be met:

(1) Avoiding high-speed rotations during the process;

(2) Basing the weight of the slurry on the width of the mixing head leaf, the immersion depth, and the outer cylinder;

(3) Using the average of multiple torque measurements to reduce the experimental error.

\subsection{Rheological Properties of the Paste-Like Slurry}

The rheological parameters of the filling slurry can be used to evaluate the pipe resistance of the slurry, that is, the head loss. There are many filling processes for coal mines, and the materials used are also different. They directly affect the solidification performance of the filling body. Therefore, the content of each material needs to be within a specific interval.

The experiments were carried out as described below, and the experimental data were fitted by ORIGIN.

(1) Five different mass concentrations were chosen: $74 \%, 75 \%, 76 \%$, $78 \%$, and $79 \%$. Table 6 presents the ratios of the slurry composition at different mass concentrations. 
Table 6. Ratios of the slurry composition at different mass concentrations.

\begin{tabular}{ccccc}
\hline Mass Concentration & Gangue (g) & Fly Ash (g) & Portland Cement (g) & Water (g) \\
\hline $74 \%$ & 296 & 113.8 & 34.2 & 156 \\
$75 \%$ & 300 & 115.4 & 34.6 & 150 \\
$76 \%$ & 304 & 116.9 & 35.1 & 144 \\
$78 \%$ & 312 & 120 & 36 & 132 \\
$79 \%$ & 316 & 121.5 & 36.5 & 126 \\
\hline
\end{tabular}

(2) With a mass concentration of $76 \%$ and a ratio of cement to fly ash of $1: 3$, the ratios of fine particles to coarse particles were varied: 1:1,1:1.5, 1:2, 1:2.5, 1:3. Table 7 presents the ratio of the slurry composition at different ratios of fine particles to coarse particles.

Table 7. Ratio of the slurry composition at different ratios of fine particles to coarse particles.

\begin{tabular}{ccccc}
\hline Ratio of Fine Particles to Coarse Particles & Gangue $(\mathrm{g})$ & Fly Ash $(\mathrm{g})$ & Portland Cement $(\mathrm{g})$ & Water (g) \\
\hline $1: 1$ & 228 & 171 & 57 & 144 \\
$1: 1.5$ & 273.6 & 136.8 & 45.6 & 144 \\
$1: 2$ & 304 & 114 & 38 & 144 \\
$1: 2.5$ & 326 & 97.5 & 32.5 & 144 \\
$1: 3$ & 342 & 85.5 & 28.5 & 144 \\
\hline
\end{tabular}

(3) With a mass concentration of $76 \%$ and the content of the coarse particles constant, the ratios of cement to fly ash content were varied: 1:3, 1:3.5, 1:4, 1:4.5, 1:5. Table 8 presents the ratio of the slurry composition at different ratios of fly ash to cement in the slurry.

Table 8. Ratio of the slurry composition at different ratios of fly ash to cement in the slurry.

\begin{tabular}{ccccc}
\hline Ratio of Fine Particles Versus Coarse Particles & Gangue (g) & Fly Ash (g) & Portland Cement (g) & Water (g) \\
\hline $1: 3$ & 296 & 114.2 & 45.8 & 144 \\
$1: 3.5$ & 296 & 120 & 40 & 144 \\
$1: 4$ & 296 & 124.4 & 35.6 & 144 \\
$1: 4.5$ & 296 & 128 & 32 & 144 \\
$1: 5$ & 296 & 131 & 29 & 144 \\
\hline
\end{tabular}

Figure 7 shows that higher mass concentrations increased the torque at the same rotating speed. The relationship between torque and rotating speed could be determined from the fitted curve in Figure 7. According to formula (11), the rheological parameters could also be obtained. The results are in Table 9.

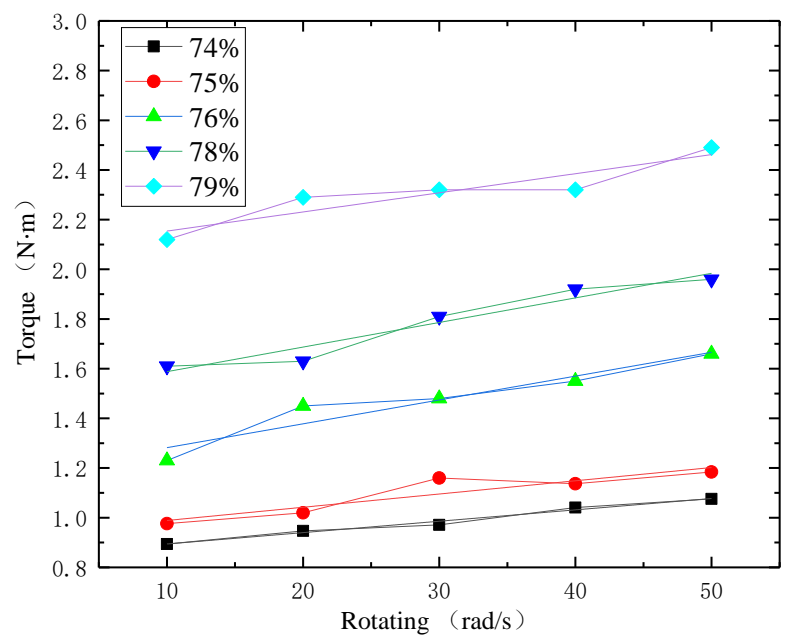

Figure 7. Relation between rotating speed and torque at different concentrations. 
Table 9. Relation between rotating speed and torque and the rheological parameters at different concentrations of the slurry.

\begin{tabular}{cccc}
\hline Concentrations & $\begin{array}{c}\text { Relation Between Rotating } \\
\text { Speed and Torque }\end{array}$ & $\begin{array}{c}\text { Viscosity } \\
\text { Coefficient (Pa.s) }\end{array}$ & $\begin{array}{c}\text { Initial Shear } \\
\text { Stress (Pa) }\end{array}$ \\
\hline $74 \%$ & $\mathrm{M}=4.33 \times 10^{-4} \omega+8.51 \times 10^{-3}$ & 2.42 & 51.89 \\
$75 \%$ & $\mathrm{M}=4.67 \times 10^{-4} \omega+9.19 \times 10^{-3}$ & 2.61 & 56.06 \\
$76 \%$ & $\mathrm{M}=4.85 \times 10^{-4} \omega+1.25 \times 10^{-2}$ & 2.71 & 76.12 \\
$78 \%$ & $\mathrm{M}=5.07 \times 10^{-4} \omega+1.66 \times 10^{-2}$ & 2.83 & 101 \\
$79 \%$ & $\mathrm{M}=5.33 \times 10^{-4} \omega+2.17 \times 10^{-2}$ & 2.98 & 132.55 \\
\hline
\end{tabular}

Figure 7 shows the relation between rotating speed and torque at different mass concentrations.

Table 9 shows the relations between rotating speed and torque that arose from different mass concentrations of the slurry, along with the resulting rheological parameters.

Figure 8 shows the relation between the viscosity coefficient and the slurry mass concentration; Figure 9 shows the relation between the initial shear stress and the slurry mass concentration.

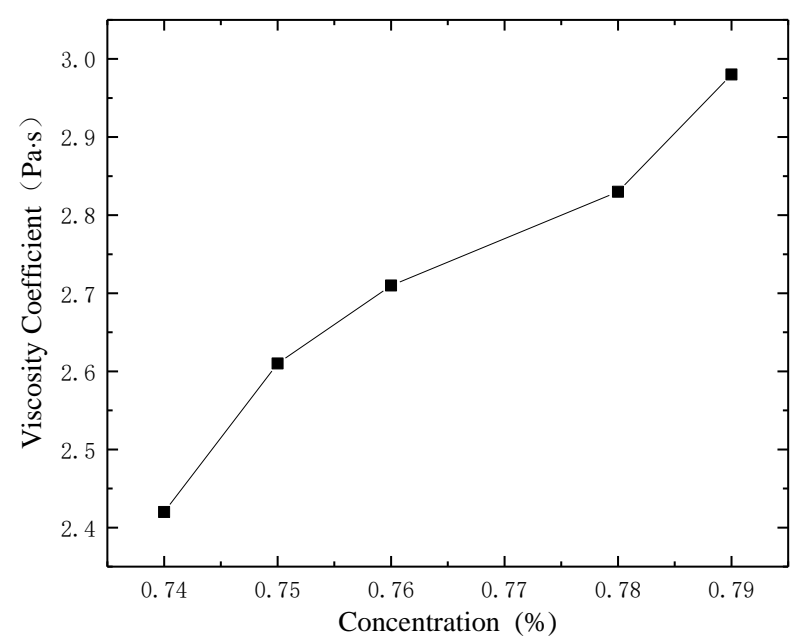

Figure 8. Relation between viscosity coefficient and slurry mass concentrations.

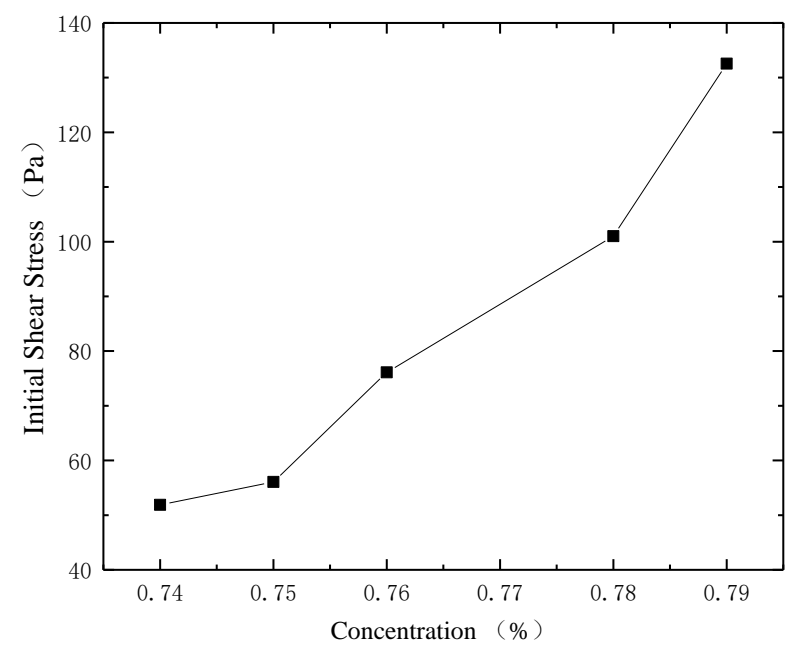

Figure 9. Relation between initial shear stress and slurry mass concentrations.

The viscosity coefficient increased with the increase in the mass concentration, but the changing trend was different at different segments of the concentration curve. The viscosity coefficient increased sharply in the $74-75 \%$ segment, while it increased gently in the $75-78 \%$ segment. The viscosity 
coefficient growth trend in the $78-79 \%$ segment was the most obvious. Considering the safety of the filling system and the transmission efficiency, the mass concentration should be controlled below $78 \%$.

The initial yield stress increased with the increase of the slurry mass concentration in the $74-79 \%$ segment, and the change trend varied with the concentration. The increase in the $74-75 \%$ segment was not obvious. Then, the increase rate was more obvious in the $75-76 \%$ segment than in the adjacent intervals. The most obvious increase trend was in the $78-79 \%$ segment. Considering the safety of the filling system and the transmission efficiency, the mass concentration should be controlled below $78 \%$.

Figure 10 shows the relation between rotating speed and torque at different ratios of fine particles to coarse particles. It shows that the torque increased with the increasing ratio of fine particles to coarse particles at the same rotating speed. The slope of the fitted curves is significantly larger than the slope of the curves in Figure 7.

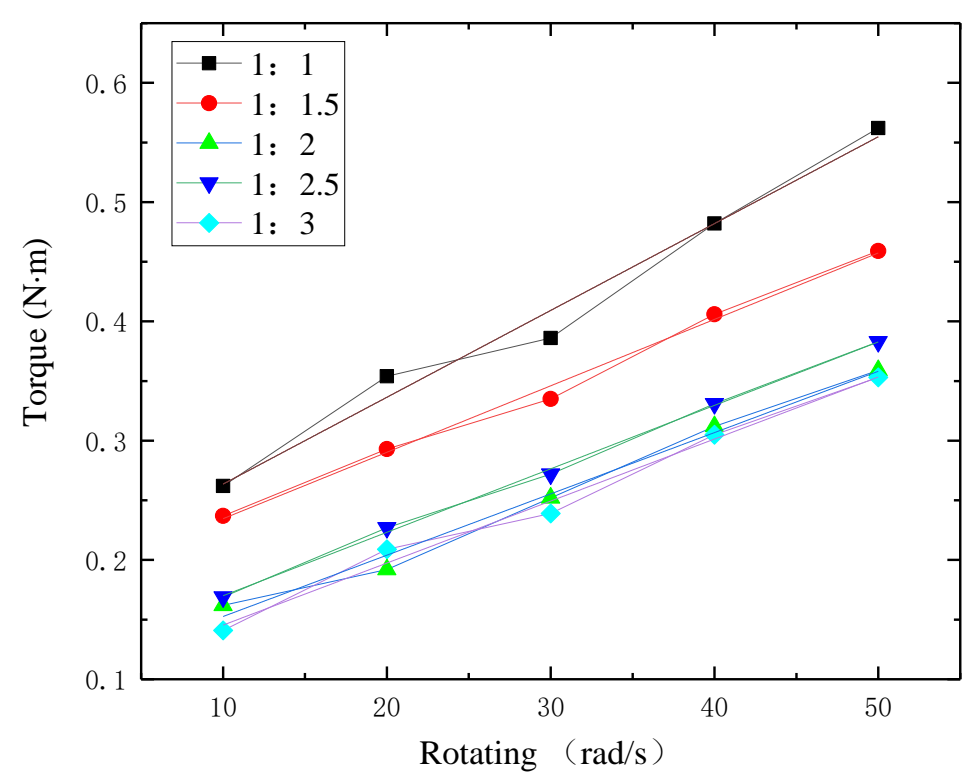

Figure 10. Relation between rotating speed and torque at different ratios of fine particles to coarse particles.

On the basis of Figure 10, Table 10 shows the relations between rotating speed and torque that arose from different ratios of fine particles to coarse particles, along with the resulting rheological parameters of the slurry.

Table 10. Relation between rotating speed and torque at different ratios of fine particles to coarse particles of the slurry and the resulting rheological parameters.

\begin{tabular}{cccc}
\hline $\begin{array}{c}\text { Ratio of Fine Particles } \\
\text { to Coarse Particles }\end{array}$ & $\begin{array}{c}\text { Relation Between Rotating } \\
\text { Speed and Torque }\end{array}$ & $\begin{array}{c}\text { Viscosity Coefficient } \\
\mathbf{( P a} \cdot \mathbf{s})\end{array}$ & $\begin{array}{c}\text { Initial Shear } \\
\text { Stress } \mathbf{( P a )}\end{array}$ \\
\hline $1: 1$ & $\mathrm{M}=6.60 \times 10^{-4} \omega+2.08 \times 10^{-3}$ & 3.67 & 126.9 \\
$1: 1.5$ & $\mathrm{M}=5.66 \times 10^{-4} \omega+1.80 \times 10^{-3}$ & 3.16 & 109.5 \\
$1: 2$ & $\mathrm{M}=5.02 \times 10^{-4} \omega+1.12 \times 10^{-2}$ & 2.96 & 68.53 \\
$1: 2.5$ & $\mathrm{M}=5.16 \times 10^{-4} \omega+1.23 \times 10^{-2}$ & 2.88 & 74.68 \\
$1: 3$ & $\mathrm{M}=4.82 \times 10^{-4} \omega+1.12 \times 10^{-2}$ & 2.69 & 68.52 \\
\hline
\end{tabular}

Figure 11 shows the relation between the viscosity coefficient and different ratios of fine particles to coarse particles; Figure 12 shows the relation between the initial shear stress and different ratios of fine particles to coarse particles. 


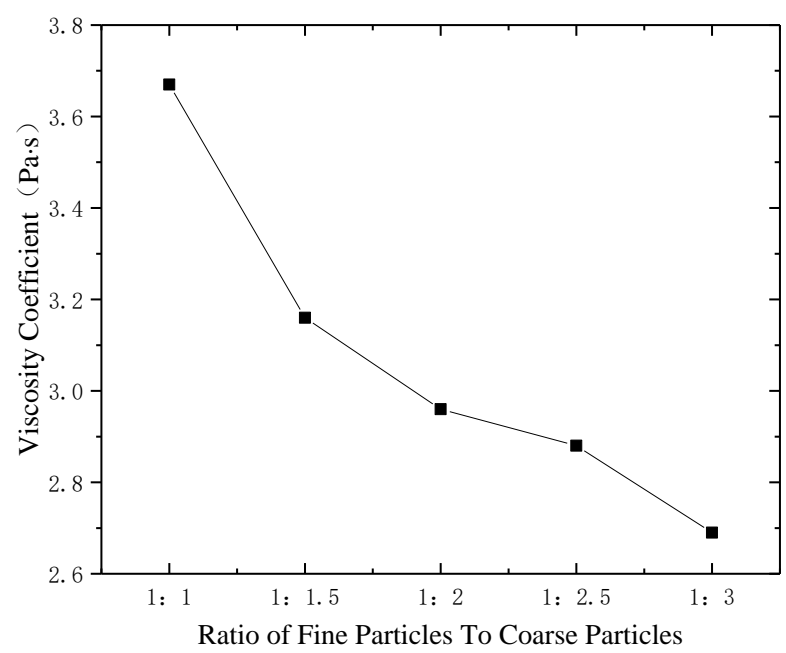

Figure 11. Relation between viscosity coefficient and different ratios of fine particles to coarse particles.

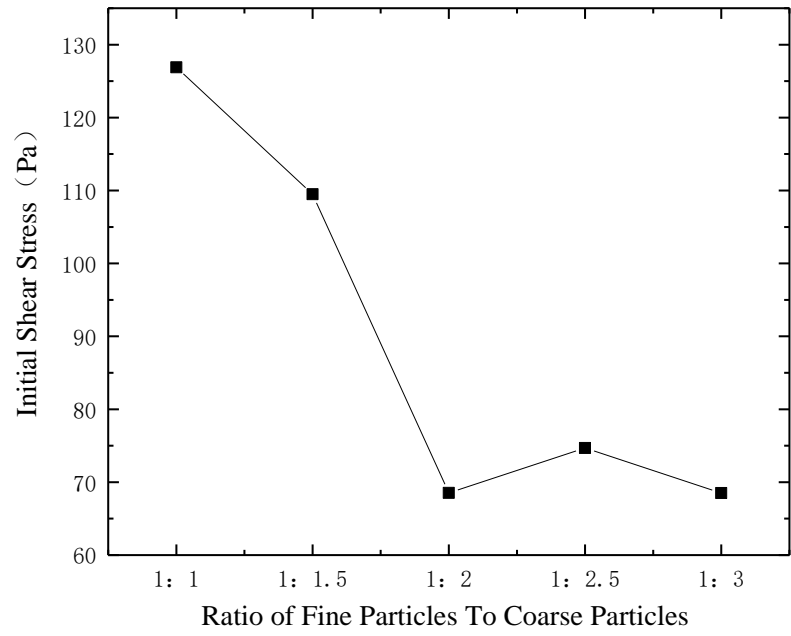

Figure 12. Relation between initial shear stress and different ratios of fine particles to coarse particles.

The curve shows that the viscosity coefficient decreased with the increase in the ratio of fine particles to coarse particles. In particular, when the ratio increased from 1:1 to 1:1.5, the viscosity coefficient decreased significantly. The decreasing trend eased slightly when the ratio increased from 1:1.5 to 1:2, but the slope was still steeper than in the 1:2 to 1:2.5 segment. The decreasing trend from 1:2.5 to 1:3 was more obvious than in the 1:2 to 1:2.5 segment. The curve shows that the fine particle concentration was the key factor driving the viscosity coefficient change. Small changes in fine particle content will cause the viscosity coefficient to change remarkably.

The curve shows that the initial yield stress tended to decrease first and then fluctuated with the increase in the ratio of fine particles to coarse particles. When the content ratio changed from 1:1 to 1:2, the initial yield stress decreased notably; however, when the content ratio increased from 1:2 to 1:2.5, the yield stress became larger. Then, the initial yield stress decreased again when the ratio changed from 1:2.5 to 1:3. It can be seen from the trend of the rheological parameters that the best ratio of fine particles to coarse particles is 1:2.

Figure 13 shows the relation between rotating speed and torque at different ratios of cement to fly ash in the slurry. It shows that the torque increased with the ratio of cement to fly ash in the slurry at the same rotating speed. The slopes of the fitted curves are roughly equal to the slopes of the curves in Figure 7. 


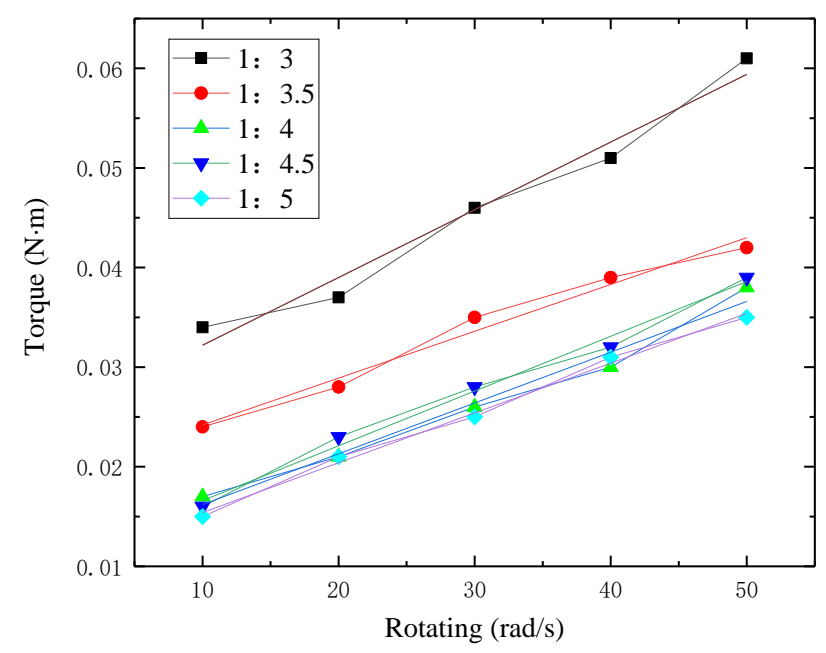

Figure 13. Relation between rotating speed and torque at different ratios of cement to fly ash in the slurry.

Table 11 shows the relations between rotating speed and torque at different ratios of fine particles to coarse particles and the resulting rheological parameters of the slurry, based on Figure 13.

Table 11. Relation between rotating speed and torque at different ratios of cement to fly ash and the resulting rheological parameters of the slurry.

\begin{tabular}{cccc}
\hline $\begin{array}{c}\text { Ratio of Cement } \\
\text { versus Fly Ash }\end{array}$ & $\begin{array}{c}\text { Relation Between Rotating and } \\
\text { Torque }\end{array}$ & $\begin{array}{c}\text { Viscosity } \\
\text { Coefficient (Pa.s) }\end{array}$ & $\begin{array}{c}\text { Initial Shear } \\
\text { Stress (Pa) }\end{array}$ \\
\hline $1: 3$ & $\mathrm{M}=4.99 \times 10^{-4} \omega+9.00 \times 10^{-3}$ & 2.79 & 54.88 \\
$1: 3.5$ & $\mathrm{M}=4.67 \times 10^{-4} \omega+9.99 \times 10^{-3}$ & 2.61 & 60.9 \\
$1: 4$ & $\mathrm{M}=5.02 \times 10^{-4} \omega+1.11 \times 10^{-2}$ & 2.81 & 67.56 \\
$1: 4.5$ & $\mathrm{M}=5.08 \times 10^{-4} \omega+1.21 \times 10^{-2}$ & 2.84 & 72.98 \\
$1: 5$ & $\mathrm{M}=5.39 \times 10^{-4} \omega+1.59 \times 10^{-2}$ & 2.99 & 109.75 \\
\hline
\end{tabular}

Figure 14 shows the relation between the viscosity coefficient and different ratios of cement to fly ash; Figure 15 shows the relation between the initial shear stress and different ratios of cement to fly ash.

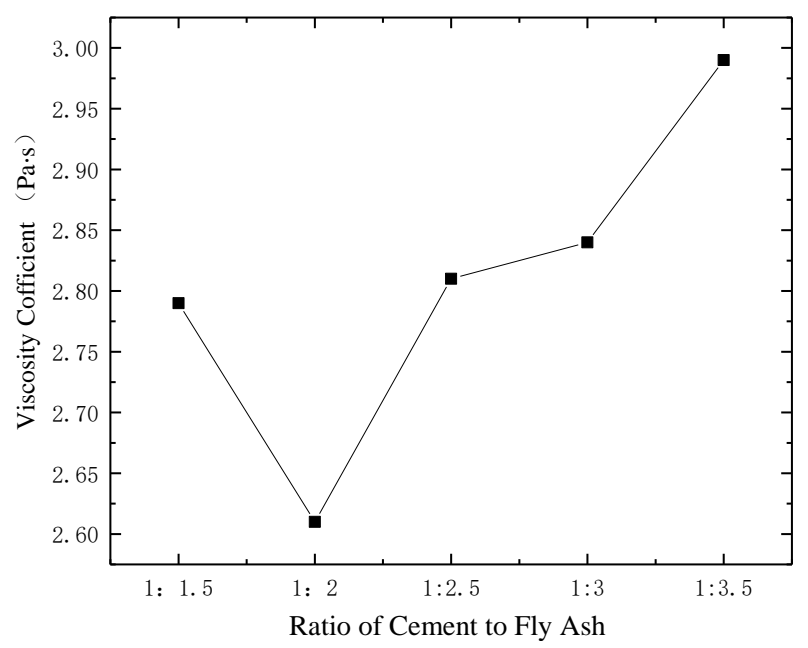

Figure 14. Relation between viscosity coefficient and different ratios of cement to fly ash. 


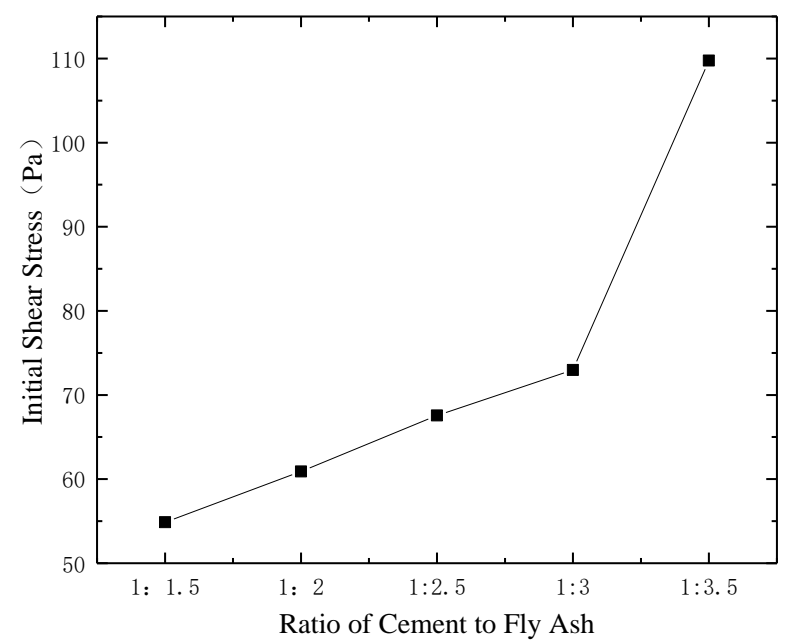

Figure 15. Relation between initial shear stress and different ratios of cement to fly ash.

The curve shows that the viscosity coefficient tended to decrease first and then increased with the ratio of cement to fly ash. When the content ratio changed from 1:1.5 to 1:2, the initial yield stress decreased; however, when the content ratio increased from 1:2 to 1:3.5, the viscosity coefficient became large. The change in the segment from 1:2 to 1:2.5 was the most obvious of all. The segment from 1:2.5 to 1:3 changed more moderately than the segment from 1:3 to 1:3.5.

The initial yield stress increased with the cement and fly ash content ratio. However, the increasing tendency for the ratio change from 1:3 to 1:3.5 was more obvious than for the change in ratio from 1:1.5 to 1:3. Considering that the cost of cement is higher than that of fly ash, the cement content should be reduced as much as possible, i.e., with minimal sacrifice of the filling body's strength. Taking into account the slurry's flowability and the filling cost, the best ratio of cement to fly ash content is 1:3. In summary, the optimum ratio of Portland cement to fly ash to gangue is 1:3:8.

\section{Evaluation of the Effectiveness of Slurry Filling}

The paste-like slurry described in this paper was utilized in the Xinyang Coal Mine. The single-strike longwall mining method was used in this mine, with a mining height of $2.2 \mathrm{~m}$. The average dip angle of the coal seam was $6^{\circ}$, and the average strike length of the working face was $569.7 \mathrm{~m}$. The production capacity was 4.7 million $\mathrm{t} / \mathrm{a}$. The mining process alternated with the filling process. The mining face layout and filling face layout are shown in Figure 16.

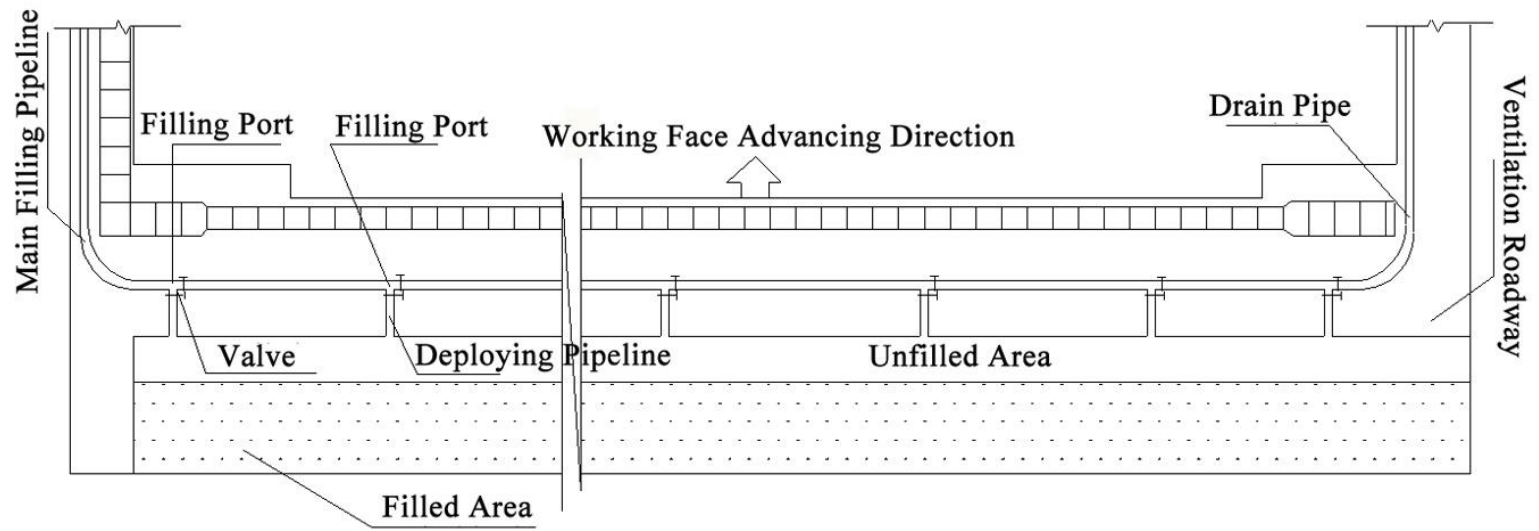

Figure 16. Layout diagram of the filling face.

According to the "Safety Regulations for Coal Mines (2016)" [27], coal pillars are left under the coal mine industrial square facilities to protect these constructions from subsidence and damage. 
The filling process of Xinyang Coal Mine was divided into two stages: The first stage consisted of filling by using high-concentration cementation filling at the front of the industrial square facilities. The use of a water-reducing admixture can retain the fluidity of the slurry with less water content, which is a unique feature of this filling method. This slurry was made of cement, fly ash, gangue, and a water-reducing admixture. The ratio of cement/fly ash/gangue/water-reducing admixture was 1:2:5:0.1. The mass concentration of the slurry was $74 \%$. During the second stage, because of the presence of a large number of buildings and agricultural facilities on the surface, a smaller surface sink was allowed. The paste-like slurry filling method was used at this stage. The surface sink data was obtained by a monitoring station on the surface. The layout of the surface monitoring points is shown in Figure 17.

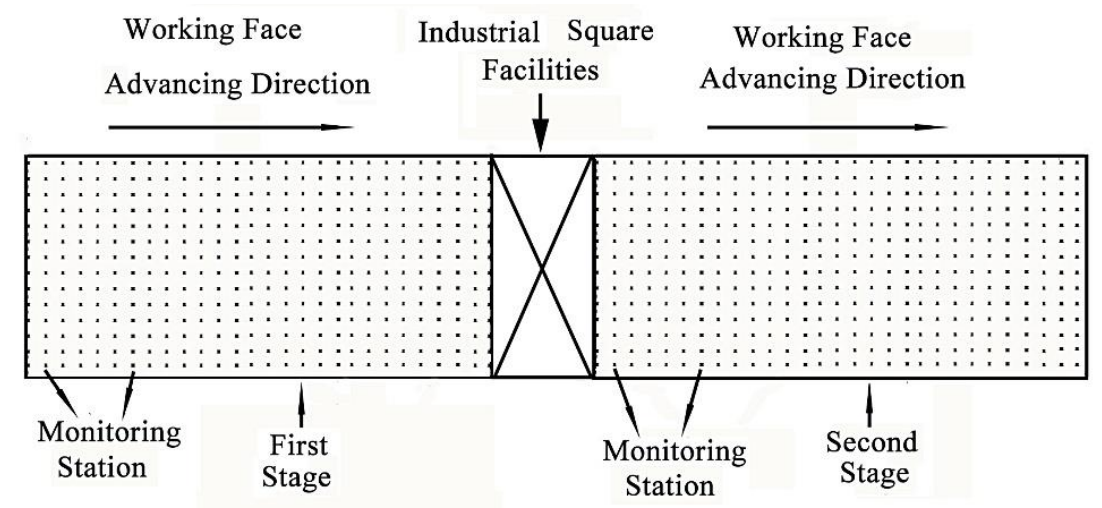

Figure 17. Layout diagram of the monitoring stations.

Table 12 presents the brick-concrete structure damage grades from the standard of the China Coal Association. Table 13 presents the surface deformation after using the high-concentration filling slurry. Table 14 presents the surface deformation after filling with the paste-like slurry. According to the "Building, Water Body, Railway and Main Mine Road Coal Pillar Retention and Coal Mining Regulations" [28] enacted by the China Coal Association, the surface deformation of the high-concentration cement filling process is graded as Class II, and the surface deformation of the paste-like slurry filling process is graded as Class I, meeting the requirements for surface building protection.

Table 12. China Coal Association's brick-concrete structure damage grade system.

\begin{tabular}{|c|c|c|c|c|}
\hline \multirow{2}{*}{$\begin{array}{c}\text { Damage } \\
\text { Level }\end{array}$} & \multicolumn{3}{|c|}{ Surface Deformation } & \multirow{2}{*}{ Damage Level } \\
\hline & $\begin{array}{c}\text { Horizontal } \\
\text { Deformation } \varepsilon(\mathrm{mm} / \mathrm{m})\end{array}$ & $\begin{array}{c}\text { Curvature } k \\
\left(10^{-3} / \mathrm{m}\right)\end{array}$ & $\begin{array}{l}\text { Tilt Angle } i \\
(\mathrm{~mm} / \mathrm{m})\end{array}$ & \\
\hline I & $\leq 2.0$ & $\leq 0.2$ & $\leq 3.0$ & Negligible Damage or Slight Damage \\
\hline II & $\leq 4.0$ & $\leq 0.4$ & $\leq 6.0$ & Mild Damage \\
\hline III & $\leq 6.0$ & $\leq 0.6$ & $\leq 10.0$ & Moderate Damage \\
\hline IV & $>6.0$ & $>0.6$ & $>10.0$ & Severe Damage \\
\hline
\end{tabular}

Table 13. Surface deformation after filling with the high-concentration filling slurry.

\begin{tabular}{cccccc}
\hline $\begin{array}{c}\text { Surface } \\
\text { Deformation }\end{array}$ & $\begin{array}{c}\text { Vertical } \\
\text { Displacement } \\
(\mathbf{m m})\end{array}$ & $\begin{array}{c}\text { Horizontal } \\
\text { Displacement } \\
\mathbf{( m m})\end{array}$ & $\begin{array}{c}\text { Tilt Angle } \\
(\mathbf{m m} / \mathbf{m})\end{array}$ & $\begin{array}{c}\text { Curvature } \\
\left(\mathbf{m m} / \mathbf{m}^{\mathbf{2}}\right)\end{array}$ & $\begin{array}{c}\text { Horizontal } \\
\text { Deformation } \\
(\mathbf{m m} / \mathbf{m})\end{array}$ \\
\hline $\begin{array}{c}\text { Maximum } \\
\text { Deformation }\end{array}$ & 189 & $87 /-87$ & $3.60 /-3.60$ & $0.06 /-0.10$ & $2.03 /-2.95$ \\
\hline
\end{tabular}


Table 14. Surface deformation after filling with the paste-like slurry.

\begin{tabular}{cccccc}
\hline $\begin{array}{c}\text { Surface } \\
\text { Deformation }\end{array}$ & $\begin{array}{c}\text { Vertical } \\
\text { Displacement } \\
(\mathbf{m m})\end{array}$ & $\begin{array}{c}\text { Horizontal } \\
\text { Displacement } \\
\mathbf{( m m})\end{array}$ & $\begin{array}{c}\text { Tilt Angle } \\
(\mathbf{m m} / \mathbf{m})\end{array}$ & $\begin{array}{c}\text { Curvature } \\
\left(\mathbf{m m} / \mathbf{m}^{2}\right)\end{array}$ & $\begin{array}{c}\text { Horizontal } \\
\text { Deformation } \\
\mathbf{( m m} / \mathbf{m})\end{array}$ \\
\hline $\begin{array}{c}\text { Maximum } \\
\text { Deformation }\end{array}$ & 82 & $34 /-34$ & $1.13 /-1.13$ & $0.02 /-0.04$ & $0.57 /-1.26$ \\
\hline
\end{tabular}

The surface sink curves of the two methods are shown in Figure 18.

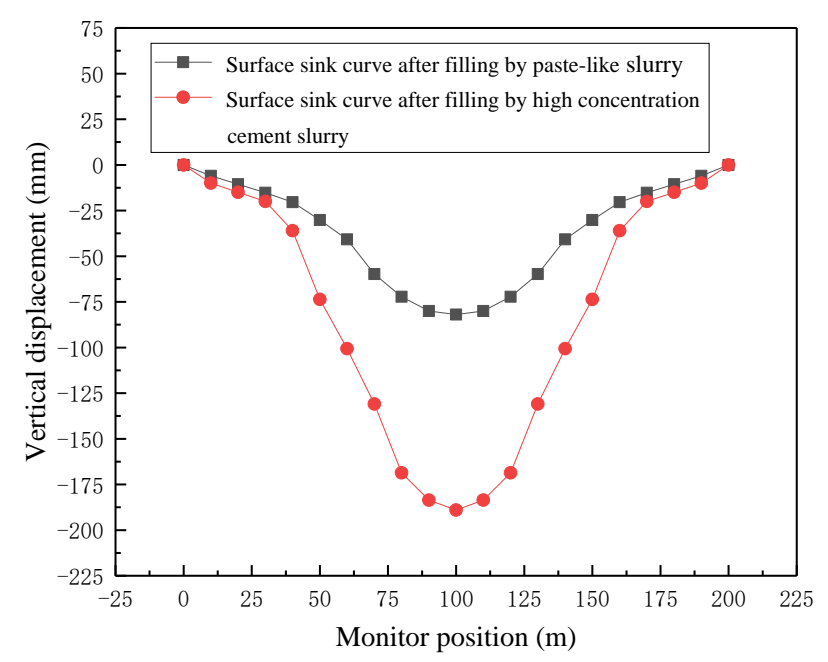

Figure 18. Surface sink curves of two filling slurries at the same filling rate.

Both surface sink-fitted curves were drawn using data collected from monitoring after six months. Figure 18 shows that: (1) the two curves are similar to a parabola and both high-concentration cementation filling and paste-like filling could effectively control surface sinking; (2) the area near the center of the goaf had the maximum surface sink; in the first stage, the variation of the radius, within a radius of $25 \mathrm{~m}$, is not very obvious, then, when the radius changed from $25 \mathrm{~m}$ to $75 \mathrm{~m}$, the sinking amount is sharply reduced from $180 \mathrm{~mm}$ to $30 \mathrm{~mm}$; in the second stage, the sedimentation amount reduced from $75 \mathrm{~mm}$ to $25 \mathrm{~mm}$; both curves have obvious changes; (3) when the radius is larger than $75 \mathrm{~m}$, the two curves tend to be gentle again, up the boundary of the goaf; (4) the amount of surface sink when filling with the paste-like slurry was about $45 \%$ of the maximum amount of the surface sink when filling with the high-concentration cement slurry, indicating that the paste-like filling can better control surface subsidence.

\section{Conclusions}

The use of coal gangue and fly ash as filling materials is of significance to the sustainable development of mining. Our experimental results show that gangue and fly ash are suitable as filling materials. For practical use, the mass concentration of the slurry and the ratio of the components need to be controlled strictly.

XRD was used to analyze the gangue and fly ash. Their composition indicates that both have high strength characteristics and can be used as filling materials to support roof stability. The intelligent torque rheometer provides a new way to obtain the rheological parameters of a slurry that contains coarse particles. The equipment can also be used for other slurries containing large particles, such as a coarse coal slurry transported by pipeline. The optimized slurry ratio is determined from the viewpoint of rheology. Determining the rheological parameters according to the curves obtained from the measurements is a convenient method that produces accurate results. 
The technology discussed in this paper is suitable for mines that employ paste-like backfilling. It may be useful to consider the strength of the optimized slurry after its consolidation with different component ratios, but that requires another research method. It may be that a lower filling rate can also control the sinking of the land surface, but this needs to be addressed by future studies.

Author Contributions: H.W. conceived and designed the experiments; H.W. and J.J. performed the experiments; H.W. and W.D. analyzed the data; Y.W. contributed analysis tools; H.W. wrote the paper.

Funding: This research received no external funding.

Conflicts of Interest: The authors declare no conflict of interest.

\section{References}

1. China National Coal Association. Available online: http://www.coalchina.org.cn/page/tjsj.htm (accessed on 20 November 2018).

2. Miao, X.X.; Qian, M.G. Research on green mining of coal resources in China: Current status and future prospects. J. Min. Saf. Eng. 2009, 26, 1-14. (In Chinese) [CrossRef]

3. Qian, M.G. On sustainable coal mining in China. J. Chin. Coal Soc. 2010, 35, 529-534. (In Chinese)

4. Li, J.; Huang, Y.; Qiao, M.; Chen, Z.; Song, T.; Kong, G.; Gao, H.; Guo, L. Effects of Water Soaked Height on the Deformation and Crushing Characteristics of Loose Gangue Backfill Material in Solid Backfill Coal Mining. Processes 2018, 6, 64. [CrossRef]

5. Liang, Y.; Liang, H.; Zhu, S. Mercury emission from spontaneously ignited coal gangue hill in Wuda Coalfield, Inner Mongolia, China. Fuel 2016, 182, 525-530. [CrossRef]

6. Wang, S.; Wang, X. Potentially useful elements (Al, Fe, Ga, Ge, U) in coal gangue: a case study in Weibei coal mining area, Shaanxi Province, northwestern China. Environ. Sci. Pollut. Res. Int. 2018, 25, 11893-11904. [CrossRef] [PubMed]

7. Miao, X.X. Progress of fully mechanized mining with solid backfilling technology. J. Chin. Coal Soc. 2012, 37, 1247-1255. [CrossRef]

8. Dickout, M.H. Filling effect on mining and properties of backfill materials. In Proceedings of the Jubilee Symposium on Mine Filling, North West Queensland Branch, Australia, August 1973; pp. 6-12.

9. Feng, G.M. Research on the Superhigh-water Packing Material and Filling Mining Technology and Their Application. Ph.D. Thesis, China University of Mining and Technology, Xuzhou, China, 2009.

10. Sun, H.; Liu, Q.; Liu, W. Commercial scale trial of a new consolidated backfill technology of full-range tailings with high water content. Nonferrous Met. 1993, 45, 7-13.

11. Zhao, C.; Hu, N. Development and application of cementing filling material. Gold 2008, 29, 25-29. [CrossRef]

12. Wang, X.; Xiao, W.; Wang, X.; Xiao, Z. Study on rheological properties of full tailing paste filling slurry of Jinchuan mine. Min. Metall. Eng. 2002, 22, 13-16. [CrossRef]

13. Soete, J.; Claes, S.; Claes, H.; Janssens, N.; Cnudde, V.; Huysmans, M.; Swennen, R. Lattice Boltzmann Simulations of Fluid Flow in Continental Carbonate Reservoir Rocks and in Upscaled Rock Models Generated with Multiple-Point Geostatistics. Geofluids. 2017, 2017. [CrossRef]

14. Lin, T. Research on the Flow Properties of the Gangue Paste-Like Slurry. Ph.D. Thesis, China University of Mining and Technology, Beijing, China, 2016.

15. Fall, M.; Pokharel, M. Coupled effects of sulphate and temperature on the strength development of cemented tailings backfill: Portland cement-paste backfill. Cem. Concr. Compos. 2010, 32, 819-828. [CrossRef]

16. Huang, Y.C. Mine Filling Theory and Technology; Metallurgical Industry Press: Beijing, China, 2014; pp. 59-60. ISBN 978-7-5024-6509-4.

17. Fei, X. Slurry and Granular Materials Conveying Hydraulics; Tsinghua University Press: Beijing, China, 1994; p. 17. ISBN 978-7-3020-1384-6.

18. Huang, Y.; Sun, H. Experimental Study on the Rheological Characteristic of Paste-like Slurry with Tailings as Aggregate. Metal Mine 2003, 324, 8-10. [CrossRef]

19. Fall, M.; Benzaazous, M.; Ouellet, S. Experiment characterization of the influence of tailings fineness and density on the quality of cemented paste backfill. J. Mater. Sci. 2005, 18, 41-44. [CrossRef]

20. Qiu, Z.; Cao, T.; Li, Y.; Wang, J.; Chen, Y. Rheological Behavior and Modeling of a Crushed Sandstone-Mudstone Particle Mixture. Processes 2018, 6, 192. [CrossRef] 
21. Fan, H.; Guo, Z.; Huang, W. Experiment of Mechanics Properties of Gangue Cementing Stowing Body. Coal Min. Technol. 2015, 20, 83-86. [CrossRef]

22. Wang, Y.; Zhu, W.; Xie, G. Comparative analysis on the structure and properties of two paste-like cemented materials. Nonferrous Met. (Min. Sec.) 2017, 69, 71-75. [CrossRef]

23. Wang, J.; Li, Y.; Zhou, X.; Wu, L.; Wei, S. Ground movement caused by mining under thick alluvium. J. Chin. Coal Soc. 1997, 22, 18-21. [CrossRef]

24. Guo, G.; Wang, Y.; Ma, Z. A new method for ground subsidence contral in coal mining. J. Chin. Univ. Min. Technol. 2004, 33, 150-153. [CrossRef]

25. Xu, J.; You, Q.; Zhu, W. Theoretical study of strip filling to control mining subsidence. J. Chin. Coal Soc. 2007, 32, 119-122. [CrossRef]

26. Zhao, J.; Liu, C.; Li, J.; Wang, W. Three-Dimensional geological modeling and surface damage in gully area due to shallow coal seam mining. J. Min. Saf. Eng. 2018, 35, 969-977.

27. State Administration of Work Safety. Safety Regulations for Coal Mines. Available online: http://www. chinasafety.gov.cn/ (accessed on 20 November 2018).

28. National Coal Mine Safety Administration. Building, Water Body, Railway and Main Mine Road Coal Pillar Retention and Coal Mining Regulations. Available online: http:/ /www.chinacoal-safety.gov.cn/ (accessed on 20 November 2018).

(C) 2018 by the authors. Licensee MDPI, Basel, Switzerland. This article is an open access article distributed under the terms and conditions of the Creative Commons Attribution (CC BY) license (http:// creativecommons.org/licenses/by/4.0/). 